\title{
Construction and case study of total factor evaluation index system of power generation enterprises
}

\author{
$Y i \mathrm{Li}^{1}$ \\ ${ }^{1}$ Huadian Electric Power Research Institute Co., Ltd., Hangzhou, China
}

\begin{abstract}
The electric power enterprises cannot cope with the current electric power system reform trend If they do not have enough competition abilities. Therefore, how to construct competitiveness evaluation system for power enterprises according to the characteristics of power market plays an important role in improving the scientific management level of electric power enterprises. This paper designs the evaluation system of total factor competitiveness of power generation enterprises, including market force, marketing force, development force, reliability, economy, flexibility, environmental protection. Analytic hierarchy process and fuzzy comprehensive evaluation method are used to determine the weight and the final evaluation basis.
\end{abstract}

\section{The introduction}

With the deepening of China's electric power system reform, power generation enterprises, especially the regional power generation enterprises with multi-source power, are facing the new normal of economy, new power transformation and the complex and changeable new situation of energy industry. How to cultivate and enhance the market competitiveness on the basis of inheritance, grasp the market opportunities, meet the challenges, and further enhance the status and influence of the industry will become a common issue for the power system industry. The competitive elements of power market of power generation enterprises should be oriented by low cost and high benefit, create the goal of maximizing economic benefit, realize efficient production, economic operation and benefit marketing, configure and perfect production and marketing system and evaluation mechanism, and help improve the overall competitiveness of enterprises in the market. In other words, we should try to achieve as much generating capacity as possible, as low cost as possible, and as high quotation as possible in the electricity market.

Therefore, the following factors should be taken into account when considering the competitive factors of power generation enterprises in the electricity market. (1) Profitability. The profitability of competitive elements is mainly reflected in reducing costs, improving quotations and creating profits, bringing considerable value and benefits to enterprises. (2) Economy. Multi-source power generation enterprises involve wind power, photovoltaic power, hydropower, thermal power and other forms of energy. Economic operation requires improving market competitiveness by optimizing economic operation mode, optimizing allocation of power generation resources and power structure, and optimizing maintenance arrangements. (3) Safe and reliable. Safety and stability of electric power production is the basic condition for power generation enterprises to create economic benefits. (4) High efficiency and energy saving. We promote the innovation of production technology and enhance the competitiveness by means of energy saving, consumption reduction and energy utilization efficiency. (5) Environmental protection. The competitiveness of power generation enterprises involving thermal power should highlight environmental factors, mainly in clean emission. At present, many research results have solved the problem of power generation enterprise competitiveness evaluation to a certain extent, but at the same time, due to the incomplete index system, the evaluation results lack of practicality and guidance. More often, power generation enterprises invest less in competitiveness evaluation, and often use the form of empirical judgment to identify the competitiveness, which may easily lead to problems such as incomplete consideration of factors and inaccurate judgment results, directly affecting the competitive decisions of power generation enterprises in the market. In view of this, this paper constructs the competitiveness evaluation system of total factor power generation enterprises, and determines the evaluation method, in order to play a practical role in the evaluation of power generation enterprises.

\section{Construction of evaluation index of total factor competitiveness of power generation enterprises}

Power generation enterprises involving multi-source power usually cover thermal power, hydropower, wind power, photovoltaic and other power generation systems.

\footnotetext{
yi-li@chder.com
} 
In the market environment, competitive factors mainly include: (1) Quantity. The quantity mainly reflects the competitiveness of power generation enterprises in the export of products and services. The main influencing factors include: electricity, heat, cold capacity and other products, as well as the factors that affect the output capacity of products, such as asset optimization, network structure, equipment capacity and fuel supply. Support services and customer service. (2) Price. The price mainly reflects the competitiveness of market quotation, and the main influencing factors include: supply and demand forecasting ability, market simulation, market price forecasting technology, quotation technology, policy and market research ability, etc. (3) Cost. The cost mainly reflects the cost competitiveness of external products of power generation enterprises, which mainly includes fixed cost and variable cost as well as related factors affecting cost, among which variable cost is the key factor of market competition.

Based on the quantity, price and cost as a starting point, this paper combines marketing work flow mechanism and core competitive factors of wind power, solar, hydropower, thermal power generating system, in the building of index, follows the scientific, comparable, growth, systematic, quantifiable indicators, such as design principles, to obtain objective and accurate evaluation results.

According to the above principles, after investigating specific power generation enterprises and consulting the opinions of many experts in the industry, the competitiveness evaluation will be finally determined from the seven aspects of market power, marketing power, development power, reliability, economy, flexibility and environmental protection, as shown in table 1 .

Table 1. Total factor competitiveness evaluation index.

\begin{tabular}{|c|c|c|}
\hline NO. & Index 1 & Index 2 \\
\hline 1 & \multirow{4}{*}{$\begin{array}{c}\text { Market } \\
\text { power(B1) }\end{array}$} & Market share (C11) \\
\hline 2 & & $\begin{array}{l}\text { Priority generation } \\
\text { capacity ratio }(\mathrm{C} 12)\end{array}$ \\
\hline 3 & & $\begin{array}{c}\text { Base power ratio } \\
\text { (C13) }\end{array}$ \\
\hline 4 & & $\begin{array}{c}\text { Network structure } \\
\text { (transport capacity) } \\
\text { (C14) }\end{array}$ \\
\hline 5 & \multirow{6}{*}{$\begin{array}{l}\text { Marketing } \\
\text { force (B2) }\end{array}$} & $\begin{array}{l}\text { Market share of } \\
\text { electricity }(\mathrm{C} 21)\end{array}$ \\
\hline 6 & & $\begin{array}{c}\text { Market price reduction } \\
\text { rate }(\mathrm{C} 22)\end{array}$ \\
\hline 7 & & $\begin{array}{c}\text { heating plan } \\
\text { completion rate }(\mathrm{C} 23)\end{array}$ \\
\hline 8 & & $\begin{array}{l}\text { Abandon wind, light } \\
\text { and water rate (C24) }\end{array}$ \\
\hline 9 & & $\begin{array}{l}\text { Heating charges } \\
\text { recovery rate (C25) }\end{array}$ \\
\hline 10 & & $\begin{array}{l}\text { Electricity charges } \\
\text { recovery rate }(\mathrm{C} 26)\end{array}$ \\
\hline 11 & \multirow{2}{*}{$\begin{array}{l}\text { Developme } \\
\text { nt (B3) }\end{array}$} & $\begin{array}{c}\text { Research } \\
\text { funding }(\mathrm{C} 31)\end{array}$ \\
\hline 12 & & $\begin{array}{l}\text { Sales growth rate } \\
\text { (C32) }\end{array}$ \\
\hline
\end{tabular}

\begin{tabular}{|c|c|c|}
\hline 13 & & Unit life (C33) \\
\hline 14 & & $\begin{array}{c}\text { Annual new } \\
\text { authorized installed } \\
\text { capacity }(\mathrm{C} 34)\end{array}$ \\
\hline 15 & & $\begin{array}{c}\text { Clean energy installed } \\
\text { capacity (C35) }\end{array}$ \\
\hline 16 & \multirow{4}{*}{$\begin{array}{l}\text { Reliability } \\
\text { (B4) }\end{array}$} & $\begin{array}{l}\text { Equivalent availability } \\
\text { coefficient (C41) }\end{array}$ \\
\hline 17 & & $\begin{array}{l}\text { Unplanned outage } \\
\text { factor (C42) }\end{array}$ \\
\hline 18 & & $\begin{array}{l}\text { Planned generation } \\
\text { completion rate }(\mathrm{C} 43)\end{array}$ \\
\hline 19 & & $\begin{array}{c}\text { Maintenance quality } \\
\text { (C44) }\end{array}$ \\
\hline 20 & \multirow{6}{*}{$\begin{array}{l}\text { Economy } \\
\text { (B5) }\end{array}$} & $\begin{array}{l}\text { Marginal contribution } \\
\text { per kilowatt hour } \\
\text { (C51) }\end{array}$ \\
\hline 21 & & $\begin{array}{l}\text { Marginal contribution } \\
\text { of heating units (C52) }\end{array}$ \\
\hline 22 & & $\begin{array}{c}\text { Power coal } \\
\text { consumption (C53) }\end{array}$ \\
\hline 23 & & $\begin{array}{l}\text { Integrated power } \\
\text { utilization (C54) } \\
\end{array}$ \\
\hline 24 & & $\begin{array}{l}\text { Profit of transferred } \\
\text { electric quantity (C55) }\end{array}$ \\
\hline 25 & & $\begin{array}{l}\text { Profit from power } \\
\text { generation rights } \\
\text { trading (C56) }\end{array}$ \\
\hline 26 & \multirow{4}{*}{$\begin{array}{l}\text { Flexibility } \\
\text { (B6) }\end{array}$} & $\begin{array}{l}\text { Peak shaving power } \\
\text { supply ratio (C61) }\end{array}$ \\
\hline 27 & & $\begin{array}{l}\text { AGC corresponding } \\
\text { time (C62) }\end{array}$ \\
\hline 28 & & $\begin{array}{c}\text { Peak and frequency } \\
\text { modulation ability } \\
\text { (C63) }\end{array}$ \\
\hline 29 & & $\begin{array}{c}\text { Rotary reserve } \\
\text { compensation (C64) }\end{array}$ \\
\hline 30 & \multirow{3}{*}{$\begin{array}{l}\text { Environmen } \\
\text {-tal } \\
\text { protection } \\
\text { (B7) }\end{array}$} & $\begin{array}{c}\text { Penalty of } \\
\text { environmental } \\
\text { protection electricity } \\
\text { price }(\mathrm{C} 71)\end{array}$ \\
\hline 31 & & $\begin{array}{c}\text { Standard discharge } \\
\text { rate }(\mathrm{C} 72)\end{array}$ \\
\hline 32 & & $\begin{array}{c}\text { Environmental } \\
\text { subsidies (C73) }\end{array}$ \\
\hline
\end{tabular}

\section{Index weighting and competitiveness evaluation method}

We need a set of scientific evaluation model and method to scientifically evaluate the core competitiveness of power generation enterprises according to the above index system. Through the evaluation, the real situation of the enterprise can be reflected truthfully. In this paper, fuzzy comprehensive evaluation method is applied, which is a widely used method and obtains good results in other fields. On the basis of competitiveness index system, the evaluation model of power generation enterprise competitiveness is constructed.

\subsection{Determination of index weight}


Reasonable weight determination plays a decisive role in comprehensive evaluation. Here, we use analytic hierarchy process (AHP) to determine the weight of indicators. AHP was proposed by American scholar T.L. Saaty in 1977. AHP method, the basic idea is to divide complex things into several orderly level, set up a description system features or characteristics of internal independent class hierarchy. According to the judgment of an objective thing, we construct the "comparative judgment matrix". Based on the maximum eigenvalue of the matrix and its corresponding eigenvector, and on the premise of passing the consistency test, the weight of relative importance order of each element in each level is determined; Through the analysis of each level, the analysis of the whole problem is derived, that is, the total ranking weight.

(1) Build hierarchical model.

The highest level refers to the purpose of the decision and the problem to be solved. The lowest level refers to alternatives when making decisions. The middle layer refers to the factors to be considered and the criteria for decision-making. For the two adjacent layers, the upper layer is called the target layer and the lower layer is called the factor layer.

(2) Construct judgment matrix.

The essence of the judgment matrix is a subjective judgment process, decision maker or relevant expert compare the relative importance of the factors related to this level in pairs. The judgment matrix has the following properties.

$$
b_{\mathrm{ij}}=1 / b_{\mathrm{ij}}
$$

The scale method of judgment matrix element $b$ ij is as follows.

Table 2. Scaling method for matrix element $b_{\mathrm{ij}}$

\begin{tabular}{|c|c|}
\hline Factor i over factor $\mathbf{j}$ & $\begin{array}{c}\text { Quantitative } \\
\text { values }\end{array}$ \\
\hline As important & 1 \\
\hline A little important & 3 \\
\hline More important & 5 \\
\hline Highly important & 7 \\
\hline Extremely important & 9 \\
\hline $\begin{array}{c}\text { Intermediate value of two } \\
\text { adjacent judgments }\end{array}$ & $2,4,6,8$ \\
\hline
\end{tabular}

(3) Calculate the characteristic roots $\lambda_{\max }$ of the judgment matrix.

The square root method is used here. The normalization of each component of the eigenvector is the weight value of the corresponding element of the same level for a factor of the upper level.

(4) Hierarchical ranking and consistency test of judgment matrix.
According to the above evaluation index system, the indexes of the main criterion layer, namely the first-level indexes, are:

$X=\left(X_{1}, X_{2}, X_{3}, X_{4}, X_{5}, X_{6}, X_{7}\right)$;

Sub-criteria layer indicators, namely secondary indicators are:

$$
\begin{aligned}
& X_{1}=\left(X_{11}, X_{12}, X_{13}, X_{14}\right), \\
& X_{2}=\left(X_{21}, X_{22}, X_{23}, X_{24}, X_{25}, X_{26}\right), \\
& X_{3}=\left(X_{31}, X_{32}, X_{33}, X_{34}, X_{35}\right), \\
& X_{4}=\left(X_{41}, X_{42}, X_{43}, X_{44}\right), \\
& X_{5}=\left(X_{51}, X_{52}, X_{53}, X_{54}, X_{55}, X_{56}\right), \\
& X_{6}=\left(X_{61}, X_{62}, X_{63}, X_{64}\right), \\
& X_{7}=\left(X_{71}, X_{72}, X_{73}\right),
\end{aligned}
$$

Let the weight of principal criterion layer B to target layer $\mathrm{A}$ be set as B1, B2, B3, B4, B5, B6, B7 respectively, and $\sum_{i=1}^{7} B_{i}=1$, the corresponding weight matrix is $\mathrm{B}=(\mathrm{B} 1, \mathrm{~B} 2, \mathrm{~B} 3, \mathrm{~B} 4, \mathrm{~B} 5, \mathrm{~B} 6, \mathrm{~B} 7)$. The weight of sub-criterion layer $\mathrm{C}$ to the main criterion layer $\mathrm{B}$ is $\mathrm{W} 1, \mathrm{~W} 2, \mathrm{~W} 3, \mathrm{~W} 4, \mathrm{~W} 5, \mathrm{~W} 6, \mathrm{~W} 7$ respectively, and

$\sum_{\mathrm{i}=1}^{7} \mathrm{~W}_{\mathrm{i}}=1$, The corresponding weight matrix is:

$W_{1}=\left(W_{11}, W_{12}, W_{13}, W_{14}\right)$,

$W_{2}=\left(W_{21}, W_{22}, W_{23}, W_{24}, W_{25}, W_{26}\right)$,

$W_{3}=\left(W_{31}, W_{32}, W_{33}, W_{34}, W_{35}\right)$,

$W_{4}=\left(W_{41}, W_{42}, W_{43}, W_{44}\right)$,

$W_{5}=\left(W_{51}, W_{52}, W_{53}, W_{54}, W_{55}, W_{56}\right)$,

$W_{6}=\left(W_{61}, W_{62}, W_{63}, W_{64}\right)$,

$W_{7}=\left(W_{71}, W_{72}, W_{73}\right)$,

If hierarchical ordering can be confirmed, consistency test is required. Where, the unique non-zero characteristic root of $n$-order uniform matrix is $n$; The maximum characteristic root of $n$-order positive reciprocal matrix $A$, if and only if $\lambda=n, A$ is an uniform matrix. Consistency indicators are defined as:

$$
C I=(\lambda-n) /(n-1)
$$

$\mathrm{CI}=0$, complete consistency; $\mathrm{CI}$ is close to 0 , with satisfactory consistency; The larger $\mathrm{CI}$ is, the more serious the inconsistency is. To measure the size of CI, random consistency index RI is introduced:

$$
R I=\left(C I_{1}+C I_{2}+\ldots+C I_{n}\right) / n
$$

In general, the higher the order of matrix, the higher the probability of consistent random deviation.

$$
C R=C I / R I
$$

If $\mathrm{CR}<0.1$, it is considered that the hierarchical ordering has a satisfactory consistency; otherwise, it is necessary to adjust and modify the judgment matrix of this level until the overall ordering of the hierarchy reaches a satisfactory consistency.

(5) The total weight conclusion is drawn.

\subsection{Competitiveness evaluation method}

(1) Determine the set of judgment comments.

For the above-mentioned evaluation index system, according to the concept of enterprise competitiveness, the following comment set is adopted: $Y=(Y 1, Y 2, Y 3$, 
Y4, Y5 $)=\{$ Strong, Secondary Strong, Medium, Weak, Poor\}.

(2) Establish fuzzy evaluation matrix.

Fuzzy evaluation matrix $A i$ ( $\mathrm{I}=1,2,3,4,5,6,7)$ is established for each evaluation index $\mathrm{Xi}$ in the main criteria layer. By considering the classification factor index $\mathrm{Xij}$ in layer $\mathrm{C}$, the degree of its subordination to the t-th evaluation $Y t$ is judged to be $r_{i j t}$, and Xi's fuzzy evaluation matrix Ri can be obtained. For example,

$$
R_{I}=\left[\begin{array}{lllll}
r_{111} & r_{112} & r_{113} & r_{114} & r_{115} \\
r_{121} & r_{122} & r_{123} & r_{124} & r_{125} \\
r_{131} & r_{132} & r_{133} & r_{134} & r_{135} \\
r_{141} & r_{142} & r_{143} & r_{144} & r_{145}
\end{array}\right]
$$

Now we can determine the fuzzy comprehensive discriminant set $\mathrm{Ai}$ of the first-level indicators. We use $\underline{\mathrm{Ai}}=\mathrm{Wi} \circ \mathrm{Ri}(\mathrm{I}=1,2,3,4,5,6,7)$ to obtain the comprehensive fuzzy discriminant set $\mathrm{Ai}=($ ai1, ai2, ai3, ai4, ai5).

$$
\begin{aligned}
& \underline{A}_{1}=W_{1} \circ R_{1}=\left(a_{11}, a_{12}, a_{13}, a_{14}, a_{15}\right) \text {, } \\
& \underline{A}_{2}=W_{2} \circ R_{2}=\left(a_{21}, a_{22}, a_{23}, a_{24}, a_{25}\right) \text {, } \\
& \underline{A}_{3}=W_{3} \circ R_{3}=\left(a_{31}, a_{32}, a_{33}, a_{34}, a_{35}\right) \text {, } \\
& \underline{A}_{4}=W_{4} \circ R_{4}=\left(a_{41}, a_{42}, a_{43}, a_{44}, a_{45}\right) \text {, } \\
& \underline{A}_{5}=W_{5} \circ R_{5}=\left(a_{51}, a_{52}, a_{53}, a_{54}, a_{55}\right) \text {, } \\
& \underline{A}_{6}=W_{6} \circ R_{6}=\left(a_{61}, a_{62}, a_{63}, a_{64}, a_{65}\right) \text {, } \\
& \underline{A}_{7}=W_{7} \circ R_{7}=\left(a_{71}, a_{72}, a_{73}, a_{74}, a_{75}\right) \text {. } \\
& \underline{A}^{\prime}=\left(\underline{A}_{1}, \underline{A}_{2}, \underline{A}_{3}, \underline{A}_{4}, \underline{A}_{5}, \underline{A}_{6}, \underline{A}_{7}\right)^{T}
\end{aligned}
$$

Finally determine the fuzzy evaluation matrix of the evaluation object:

$$
\begin{aligned}
E & =B \circ \underline{A}=\left(e_{1}, e_{2}, e_{3}, e_{4}, e_{5}\right) \\
e_{i}^{\prime} & =e_{i} / \sum e_{i}(i=1,2,3,4,5) \\
E^{\prime} & =\left(e_{1}^{\prime}, e_{2}^{\prime}, e_{3}^{\prime}, e_{4}^{\prime}, e_{5}^{\prime}\right)
\end{aligned}
$$

ei 'corresponds to the previous comment element $\mathrm{Yi}$ respectively. From the perspective of probability, the probability in conformity of this ability and enterprise competitiveness is $\mathrm{e}_{i}$. According to the maximum membership principle in fuzzy mathematics, the core competitiveness of enterprises is evaluated.

\section{A case study on total factor competitiveness of $\mathbf{W}$ company}

$\mathrm{W}$ company is mainly engaged in hydropower, thermal

\begin{tabular}{|c|c|c|c|c|c|c|c|c|}
\hline B & B1 & B2 & B3 & B4 & B5 & B6 & B7 & $\begin{array}{c}\begin{array}{c}\text { C-level } \\
\text { ordering }\end{array} \\
\end{array}$ \\
\hline & 0.379 & 0.167 & 0.0976 & 0.057 & 0.233 & 0.04 & 0.026 & \\
\hline c1 & 0.643 & & & & & & & 0.2437 \\
\hline c2 & 0.048 & & & & & & & 0.0182 \\
\hline c3 & 0.101 & & & & & & & 0.0383 \\
\hline c4 & 0.208 & & & & & & & 0.0788 \\
\hline c5 & & 0.491 & & & & & & 0.0820 \\
\hline c6 & & 0.222 & & & & & & 0.0370 \\
\hline c7 7 & & 0.093 & & & & & & 0.0156 \\
\hline c8 & & 0.093 & & & & & & 0.0156 \\
\hline c9 & & 0.050 & & & & & & 0.0084 \\
\hline c10 & & 0.050 & & & & & & 0.0084 \\
\hline c11 & & & 0.233 & & & & & 0.0228 \\
\hline c12 & & & 0.526 & & & & & 0.0514 \\
\hline c13 & & & 0.070 & & & & & 0.0068 \\
\hline c14 & & & 0.041 & & & & & 0.0040 \\
\hline c15 & & & 0.129 & & & & & 0.0126 \\
\hline c16 & & & & 0.275 & & & & 0.0157 \\
\hline c17 & & & & 0.138 & & & & 0.0079 \\
\hline c18 & & & & 0.512 & & & & 0.0292 \\
\hline c19 & & & & 0.074 & & & & 0.0042 \\
\hline c20 & & & & & 0.486 & & & 0.1133 \\
\hline c21 & & & & & 0.122 & & & 0.0285 \\
\hline c22 & & & & & 0.225 & & & 0.0524 \\
\hline c23 & & & & & 0.037 & & & 0.0087 \\
\hline c24 & & & & & 0.065 & & & 0.0151 \\
\hline c25 & & & & & 0.065 & & & 0.0151 \\
\hline c26 & & & & & & 0.400 & & 0.0160 \\
\hline c27 & & & & & & 0.200 & & 0.0080 \\
\hline c28 & & & & & & 0.200 & & 0.0080 \\
\hline c29 & & & & & & 0.200 & & 0.0080 \\
\hline c30 & & & & & & & 0.200 & 0.0052 \\
\hline c31 & & & & & & & 0.600 & 0.0156 \\
\hline c32 & & & & & & & 0.200 & 0.0052 \\
\hline
\end{tabular}
power, new energy and coal development, which is an integrated energy enterprise. The total installed power capacity of the company is 13.245 million $\mathrm{kW}$, including 8.695 million $\mathrm{kW}$ of hydropower, 4.5 million $\mathrm{kW}$ of thermal power and $50,000 \mathrm{~kW}$ of new energy.

\subsection{Using the analytic hierarchy process (AHP) to weight the index}

By constructing the judgment matrix and hierarchy single sort, the hierarchy total sort and consistency test are completed.

Table 3. Total hierarchical ordering.

Consistency test of c-level total ranking is shown in table 4.

Table 4. Total hierarchical ordering.

\begin{tabular}{|c|c|c|c|c|c|c|c|c|}
\hline \multirow{2}{*}{ C $\mathrm{B}$} & $\mathbf{B} 1$ & B2 & B3 & B4 & B5 & B6 & B7 & \multirow{2}{*}{ index } \\
\cline { 1 - 9 } & 0.379 & 0.167 & 0.098 & 0.057 & 0.233 & 0.04 & 0.026 & \\
\hline CI & 0.058 & 0.009 & 0.019 & 0.004 & 0.015 & 0 & 0 & 0.029 \\
\hline RI & 0.9 & 1.24 & 1.24 & 0.9 & 1.24 & 0.9 & 0.58 & 1.045 \\
\hline
\end{tabular}

$C R=C I / R I=0.029 / 1.045=0.028<0.1, \quad$ so $\quad$ the consistency of the overall ranking at level $\mathrm{C}$ is satisfactory. 


\subsection{Fuzzy comprehensive evaluation and analysis}

Through questionnaire analysis and data processing, the fuzzy comprehensive analysis and evaluation of the core competitiveness of the independent power generation enterprise is conducted as follows:

(1) It is known that the weight vector of the subcriteria layer to the principal criteria layer is:

$$
\begin{aligned}
& W_{1}=\left(W_{11}, W_{12}, W_{13}, W_{14}\right)=(0.643,0.048,0.101,0.208) ; \\
& W_{2}=\left(W_{21}, W_{22}, W_{23}, W_{24}, W_{25}, W_{26}\right)=(0.491,0.222,0.093, \\
& 0.093,0.005,0.005) ; \\
& W_{3}=\left(W_{31}, W_{32}, W_{33}, W_{34}, W_{35}\right)=(0.233,0.526,0.07, \\
& 0.041,0.129) ; \\
& W_{4}=\left(W_{41}, W_{42}, W_{43}, W_{44}\right)=(0.275,0.138,0.512,0.074) ; \\
& W_{5}=\left(W_{51}, W_{52}, W_{53}, W_{54}, W_{55}, W_{56}\right)=(0.486,0.122,0.225, \\
& 0.037,0.065,0.065) ; \\
& W_{6}=\left(W_{61}, W_{62}, W_{63}, W_{64}\right)=(0.4,0.2,0.2,0.2) ; \\
& W_{7}=\left(W_{71}, W_{72}, W_{73}\right)=(0.2,0.6,0.2) .
\end{aligned}
$$

(2) The weight vector of the principal criterion layer to the target layer is:

$B=\left(B_{1}, B_{2}, B_{3}, B_{4}, B_{5}, B_{6}, B_{7}\right)=(0.379,0.167,0.0976,0.057$, $0.233,0.04,0.026)$.

(3) The following comment set is adopted: $Y=(Y 1$, $Y 2, Y 3, Y 4, Y 5)=\{$ Strong, Secondary Strong, Medium, Weak, Poor\}.

(4) Through expert investigation and analysis, the membership degree of indicator $\mathrm{Xij}$ to $\mathrm{Y}$ under factor index $\mathrm{Xi}$ of $\mathrm{C}$-layer is sorted out, and the fuzzy evaluation matrix $\mathrm{Ri}$ of $\mathrm{Xi}$ is obtained.

(5) Determine the membership degree of each index in the principal criterion layer to $\mathrm{Y}$, so as to obtain the fuzzy matrix A of $\mathrm{X}$.

$$
\begin{aligned}
& \underline{A}_{1}=W_{1} \circ R_{1}=(0.317,0.494,0.147,0.042,0), \\
& \underline{A}_{2}=W_{2} \circ R_{2}=(0.186,0.359,0.203,0.119,0.042), \\
& \underline{A}_{3}=W_{3} \circ R_{3}=(0.211,0.363,0.208,0.133,0.084), \\
& \underline{A}_{4}=W_{4} \circ R_{4}=(0.138,0.512,0.322,0.018,0.01), \\
& \underline{A}_{5}=W_{5} \circ R_{5}=(0.003,0.128,0.483,0.315,0.072), \\
& \underline{A}_{6}=W_{6} \circ R_{6}=(0.174,0.4,0.222,0.198,0), \\
& \underline{A}_{7}=W_{7} \circ R_{7}=(0.468,0.386,0.106,0.04,0) . \\
& \underline{A}=\left(\underline{A}_{1}, \underline{A}_{2}, \underline{A}_{3}, \underline{A}_{4}, \underline{A}_{5}, \underline{A}_{6}, \underline{A}_{7}\right)^{T}
\end{aligned}
$$

(6) The degree of subordination of the comment set $\mathrm{Y}$ to the total factor competitiveness of power generation enterprises

$$
\begin{aligned}
& \text { Normalization is carried out: } \\
& \sum_{i=1}^{5} e_{i}=0.984, \\
& e_{i}^{\prime}=e_{i} \sum e_{i}(i=1,2,3,4,5) \\
& E^{\prime}=\left(e_{1}, e_{2}, e_{3}, e_{4}{ }^{\prime}, e_{5}{ }^{\prime}\right)= \\
& (0.202,0.374,0.256,0.134,0.034)
\end{aligned}
$$$$
E=B \circ A=(0.199,0.368,0.252,0.132,0.033)
$$

Where, $e_{i}$ ' respectively corresponds to the previous comment set element $Y i$.

(7) From the above calculation results, it can be shown that: $20.2 \%$ of the assurance that the power generation enterprise competitiveness is strong, $37.4 \%$ of the assurance that the power generation enterprise competitiveness is strong, $25.6 \%$ of the assurance that the power generation enterprise competitiveness is general, $13.4 \%$ of the assurance that the power generation enterprise competitiveness is weak, $3.4 \%$ of the assurance that the power generation enterprise competitiveness is weak. According to the principle of maximum membership, we can judge the competitiveness of the enterprise is strong.

\section{Conclusion}

The evaluation of the competitiveness of power generation enterprises is a concept with wide coverage and complex content. In view of the multi-source power enterprises under the environment of power market, it is necessary to analyze the objective facts of enterprises based on scientific methods, take the market as the entry point, and measure them reasonably.

This study focuses on the analysis of the power market elements of power generation enterprises, namely, from the seven aspects of enterprise market power, marketing power, development power, reliability, economy, flexibility and environmental protection to evaluate the sustainable development ability and market competitiveness of enterprises. We have integrated the domestic and foreign evaluation indexes, and introduced the relevant indexes in the power marketing, which is more conducive to the enterprise to clarify the advantages and disadvantages in the strategic planning.

\section{Acknowledgement}

The auther gratefully acknowledge the contributions of the Science and technology project of China Huadian Corporation Ltd. ( CHDKJ18-02-127) and (CHDKJ1802-192)

\section{References}

1. Wenxun Li, Changing Yao, Zhihui Liu. China Science \& Technology Resources Review[J]. 49, (2017) : 75-82

2. Qin Wang, Fushuan Wen, Min Liu. Su Yi. Electric Power Technologic Economics[J]. 20, (2008):21-26

3. Lei Guo, Bin Wei, Qing Xia, Yan Zhuang. Li Ma. Electric Power Technologic Economics[J]. 20, (2008):29-34

4. Lei Guo, Bin Wei, Qing Xia, Yan Zhuang. Li Ma. Journal of North China Electric Power University[J]. 33, (2006)

5. Peihua Song. Evaluation Research on Competitiveness of China's Electric Power Generation[D]. Harbin University of Science and Technology. (2011) 